\title{
I tinerários abortivos em contextos de clandestinidade na cidade do Rio de Janeiro - Brasil
}

\author{
Abortion itineraries in a clandestine context \\ in the city of Rio de Janeiro - Brazil
}

\author{
M aria Luiza Heilborn ${ }^{1}$ \\ Cristiane da Silva Cabral ${ }^{1}$ \\ Elaine Reis Brandão ${ }^{2}$ \\ Livi Faro ${ }^{1}$ \\ Fabíola Cordeiro $^{1}$ \\ Rogério LopesAzize ${ }^{3}$
}

${ }^{1}$ Centro Latino-Americano em Sexualidade Direitos Humanos, Instituto de Medicina Social, Universidade do Estado do Rio deJaneiro. RuaSão Francisco Xavier 524/70 andar/Bloco D, M aracanã. 20559-900 Rio de Janeiro RJ. sexgen@uerj.br ${ }^{2}$ Instituto de Estudos em Saúde Coletiva, UniversidadeFederal do Rio deJaneiro.

${ }^{3}$ Universidade Federal Fluminense(Camposdos Goytacazes).
Abstract From a series of in-depth interviews, we gathered a significant amount of ethnographic material on the concrete and symbolic paths taken by young women and their partners in the search for a solution to an unplanned pregnancy. Inequities in Brazilian society are expressed in itineraries/routes of different sinuosity, complexity and duration according to the individuals' social and material conditions of existence. Thus, for middle class youths access to abortion is very swift and secure, whereas for the rest of women the decision to abort consists of efforts on different levels to achieve the undertaking. The narratives may assumedramatic proportions, including abortion even in advanced stages of pregnancy. Key words Youth, Pregnancy, Abortion, Contraception, Q ualitative research, Anthropology
Resumo A partir de um conjunto de entrevistas em profundidade reuniu-se significativo material de cunho etnográfico sobre os percursos - concretos e simbólicos - de jovens mulheres e seus parceiros em busca de solução para uma gravidez imprevista. As iniquidades da sociedade brasileira se expressam em itinerários de maior ou menor sinuosidade, complexidadee duração deacordo com as condições materiais de existência e recursos sociais de que dispõem os sujeitos. Assim, para jovens de setores médios o acesso para a realização do aborto é ágil e bastante seguro, enquanto para as demais mulheres a decisão de abortar compõe-se de esforços em diferentes planos para a consecução do projeto. As narrativas podem assumir contornos dramáticos que configuram decisões de interrupção da gravidez mesmo em estágios avançados de gestação.

Palavras-chave Juventude, Gravidez, Aborto, Contracepção, Pesquisa qualitativa, Antropologia 


\section{Introdução}

A produção científica sobregênero erelações afetivas, no Brasil, conheceu nas três últimas décadas um grande impulso. A masculinidade, objeto de desconstrução deum gênero supostamente universal, foi analisada em inúmeras pesquisas sobre sexualidade. Contudo, no tocanteà reprodução, em especial, à contracepção e ao aborto, as investigações estão ainda muito centradas nas mulheres, haven do poucos estudos que incluem a perspectiva dos homens sobre uma gravidez imprevista e um provável aborto. A escassez de reflexão demonstra a permanência de uma visão naturalista da divisão do trabalho reprodutivo entre os sexos, ignorando-se que a externalidade dos homens frente ao controle da fecundidade feminina sefunda em uma concepção ocidental e contemporânea da reprodução ${ }^{1,2}$. As articulações peculiares de gênero na constituição do par e os processos decisórios na esfera reprodutiva permanecem pouco analisados.

No país, há severas restrições legais à prática do aborto. Duas possibilidades estão asseguradas (risco devida da mãee gravidez resultantede estupro) e parte da sociedade civil luta pela "antecipação cirúrgica do parto" nos casos de anencefalia fetal. 0 quadro sociopolítico apresenta-se fortementetensionado em função das investidas de diversos setores da sociedade para assegurar a proteção legal da vida humana desde a concepção. Entretanto, a ilegalidadedo aborto no Brasil não impede sua realização em condiç̧̃es muito diversas, que espelham um grave quadro de desigualdades sociais ${ }^{3}$. Ao contrário, ele desempenhou um papel muito significativo na redução da fecundidade no país 4 .

No artigo, trazemos alguns resultados da pesquisa $\mathrm{H}$ eterossexualidades, Contracepção e Aborto (HEXCA), os quais contemplam biografias de 28 jovens ( 13 homens e 15 mulheres), entre 18-27 anos, de camadas médias e populares urbanas, residentes na área metropolitana do Rio deJ aneiro, sobre suas experiências de contracepção, gravidez imprevista e aborto provocado.

Utilizamos a referência consagrada do termo "aborto" na bibliografia corrente (ao invés de "abortamento" ${ }^{5}$ ) para designar as situações em exame. A expressão "interrupção voluntária da gravidez - IVG", corrente na sociedade francesa para tratar o aborto, é incomum na literatura brasileira. Ela aponta para a autodeterminação do sujeito ao escolher o encerramento da gestação 6 e se distancia do termo médico "aborto", sinalizando para as dimensões relacionais, presen- tes em uma gravidez, que permanecem ocultas pela designação do ato. Há ainda o termo abortamento ( ou aborto) espontâneo, qualificado como decorrente de causas "naturais", forma adotada pela língua portuguesa perante a ausência de distinção entre, por exemplo, miscarriage eabortion.

A ilegalidade das práticas de interrupção da gravidez no Brasil limita a possibilidade de estimarmos a magnitude do fenômen $0^{4,7-9}$. As tentativas de conhecer a frequência com que as muIheres recorrem ao aborto induzido no país, em geral, empregam métodos variados e partem de dados encontrados em registros de aten dimento hospitalar a mulheres que recorreram a serviços de emergência em processo de abortamento incompleto. Tais investigações apontam graus variados de subdeclaração do aborto, havendo consenso de que o quadro descrito representa um patamar mínimo de ocorrência do evento nas populações estudadas ${ }^{8}$. Todavia, há quemencionar estudo pioneiro recente: Pesquisa Nacional deA borto, que realizou um levantamento por amostragem aleatória de domicílios, com muIheres urbanas, com idade entre 18-39 anos ${ }^{8}$. Os autores apontam que uma em cada cinco muIheres já fez aborto; há grande referência ao uso de medicamentos para interrupção da gravidez. A internação pós-aborto foi observada em cerca de metade dos casos declarados.

$M$ onteiro eAdesse ${ }^{10}$ afirmam queas estimativas da razão de abortos inseguros por 100 nascidos vivos no Brasil, entre os anos de 1992 e 2005, são de $43 \%$ e $30 \%$, respectivamente (estimativa realizada a partir de dados do Sistema Ú nico de Saúde - SUS) ${ }^{10}$. Os autores apontam uma razão de 2,07 abortos por 100 mulheres de 15-49 anos em 2005. 0 risco do aborto inseguro não se distribui igualmente entre a população feminina em idade fértil no país, eé uma das principais causas de mortalidade materna no Brasil.

Estudos socioantropológicos priorizam as representações e sentidos que figuram nos discursos femininos sobre a experiência do aborto. Pesquisas realizadas nas cidades de São Paulo ${ }^{11}$, Fortaleza ${ }^{12}$ e Porto Alegre ${ }^{13}$ indicam que as muIheres tendem a negar a prática ao serem inquiridas de forma direta; entretanto, declaram com maior facilidade "procedimentos de regulação menstrual" (uso de chás, beberagens com ou sem drogas abortivas) em situações de gravidez presumida ou mesmo confirmada. Uma gravidez não validada socialmente abre a possibilidade da sua interrupção, com o recurso a métodos não identificados como abortivos, mas para "fazer baixar as regras", integrando uma rotina contraceptiva ${ }^{13}$. 
Esse quadro corrobora a relevância de pesquisas que não se restrinjam a dados oficiais ou à clientela dos serviços de saúde, de modo a contemplar a diversidade e a complexidade da questão. Estratégias para a interrupção da gravidez e suas negociações no âmbito das relações familiares e afetivas e as diferentes moralidades envolvidas também precisam se tornar objeto de investigação. A proposição deuma perspectiva mais ampla de análise permite acessar informações sobre os atores, detalhamento acerca dos desdobramentos da experiência em suas trajetórias e os processos decisórios em torno da interrupção da gravidez.

\section{Metodologia}

A pesquisa HEXCA é um estudo socioantropológico baseado em entrevistas em profundidade, conduzidas a partir de roteiro padronizado esemiestruturado com os seguintes temas: dados sociodemográficos, origem e formação familiar; trajetória escolar e de trabalho; carreira afetivo-se xual; práticas contraceptivas; e eventos de gravidez e aborto. A pesquisa, coordenada pelo Centro Latino-Americano em Sexualidadee Direitos H umanos (CLAM ), Instituto de M edicina Social daUniversidade do Estado do Rio de Janeiro (Brasil), foi desenvolvida, entre 2007-2010, nas regiões metropolitanas do Rio de Janeiro, Bogotá, Buenos Aires e Montevidéu, em parceria com Universidad Nacional da Colômbia, Centro de Estudios do Estado y Sociedad, na Argentina, e Universidad de la República, no U ruguai. 0 estudo foi aprovado pelo Comitêde Ética em Pesquisa do IM S/UERJ e adotou o TCLE para todos os informantes (nenhum entrevistado/a se recusou a assiná-lo).

No Rio de Janeiro, foram entrevistadas ao todo 58 pessoas ( 30 mulheres e 28 homens), de diferentes inserções sociais (classes médias e populares - respectivamenteidentificadas como CM e CP), com ao menos um episódio de aborto provocado em suas trajetórias biográficas. Os informantes são de dois grupos etários, dado o interesse em contemplar distintas etapas da trajetória afetivo-sexual: o início da carreira sexual (18-27 anos) e o término do período reprodutivo para as mulheres (40-49 anos). No que se refere aos homens, foram entrevistados 8 rapazes de 18-27 anos de CP e 5 rapazes de CM , e 9 homens de 40-49 anos de CP e 6 homens de CM . Dentre as mulheres, a divisão por geração foi equitativa (15) e a proporção por classe social respeitou, como previsto, 10 para as CP e 5 para as CM . O conjunto dos entrevistados foi composto através de cotas previamente estabelecidas, segundo os critérios de sexo, faixa etária e inserção social. A classificação dos informantes segundo classe social considerou vários elementos: família de origem, local de residência, formação escolar e nível de renda. Embora haja significativa mobilidade social nas classes populares em função da ascensão escolar e eventualmente de renda, consideramos que a origem social eo local de residência permanecem como ele mentos de peso na configuração de determinado ethos e visão de mundo que configuram os pertencimentos sociais ${ }^{14}$.

Os contatos foram estabelecidos a partir de redes informais de sociabilidade. 0 trabalho de campo excedeu o tempo previsto (2007-8), devido a dificuldades na execução de um estudo que trata de um tema íntimo, delicado e, sobretudo, ilegal. Além disso, a pesquisa coincidiu no Brasil com uma grande mobilização social e debate na mídia em torno da denúncia e prisão de mulheres que haviam praticado 0 aborto induzido, 0 que certamente contribuiu para que as pessoas temessem falar sobre suas experiências.

Houve maior resistência da parte dos homens; a quota de mulheres foi preenchida demodo mais fácil. Os interlocutores reagiam com estranhamento sobre o fato de desejarmos depoimentos de homens acerca de abortos. 0 assunto é considerado estritamente feminino, não dizendo respeito aos homens ou sendo algo sobre o qual não tinham o que falar2,15. Em alguns casos, o possível informante justificava a recusa em participar do estudo afirmando: não ter certeza sea parceira havia engravidado dele; não saber se a moça realmente esteve grávida, já que não acompanhou o episódio de perto; só ter sabido do evento depois de ocorrido; ou que, embora alguma parceira tivesse "perdido" um bebê, ele não sabia se de fato havia sido um aborto provocado.

As entrevistas foram realizadas em locais escolhidos pelos entrevistados: em suas casas, na casa do/a pesquisador/a, em lugares próximos aos locais de trabalho, na universidade. Procurou-se assegurar a privacidade e o caráter reservado do encontro. As entrevistas foram gravadas e duraram em média 2 horas; algumas foram mais longas, desdobrando-se em dois ou até mesmo três encontros. Os pesquisadores tinham cerca de 30 anos, formação em ciências sociais e pós-graduação em saúde coletiva ou antropologia social. A maioria dos informantes foi entrevistada por um pesquisador/a do mes- 
mo sexo - com exceção daqueles que pediram o contrário. Adotamos nomes fictícios para preservar o anonimato dos testemunhos; contudo, os indexadores sociais são verídicos.

\section{Resultados eDiscussão}

\section{Perfil dos Entrevistados}

0 artigo focaliza as trajetórias de 28 jovens (15 mulheres e 13 homens), com idade entre 1827 anos, de camadas médias e populares, residentes no Rio de Janeiro. Os depoimentos femininos somam o total de 35 gestações, cujos desdobramentos foram filhos nascidos vivos (11), abortos provocados (21) e abortos espontâneos (3). As narrativas masculinas relatam o total de 23 gestações, com filhos nascidos vivos (6), abortos provocados (15) e abortos espontâneos (2); o aborto tende a ocorrer por ocasião da primeira gravidez de suas parceiras. Entre as moças, a metade dos casos registra o primeiro evento de gravidez no período de atéum ano após a iniciação sexual; nos demais, a primeira gestação ocorre de três a sete anos após o primeiro intercurso sexual.

As gestações levadas a termo estão presentes nos relatos de moças e rapazes de CP (a exceção deum caso de maternidade em moça oriunda de estratos médios). Dentre as mulheres, destaca-se a biografia de uma moça de 23 anos com 6 gestações, 2 filhos nascidos vivos (embora um deles tenha morrido com um mês de idade) e 4 abortos provocados. A gravidez imprevista raramente é levada a termo dentre os jovens de segmentos sociais mais abastados, o que contrasta com a diversidade de situações nas camadas populares. Pode-se afirmar que 0 evento reprodutivo entrejovens deorigem popular pertenceao cenário de uma transição condensada para a vida adulta em alguns casos $^{16}$.

Os dados sobre cor/raça, religião, escolaridadee renda estão reunidos para caracterizar os informantes. Os homens de CM declaram-se majoritariamente brancos (4). Entre os rapazes de CP prevalece a auto-declaração como pardos (5); doisjovens declararam-se pretos, e dois (2) brancos. A maioria das mulheres se declara parda (6), sendo cinco das CP euma das CM ; o restante (5) das jovens populares se apresenta como pretas e, as jovens médias, como brancas (4).

De acordo com o padrão dominante na juventude do país, entre os rapazes predomina a não adesão a doutrinas ou instituições religiosas, embora afirmem terem sido educados se- gundo os preceitos de alguma crença religiosa. Somente dois entrevistados (CP) afirmam ter inserção religiosa: 1 católico e 1 protestante pentecostal. Entre as moças de CM , a não adesão religiosa também é vigente; uma delas é de família evangélica e com frequência semanal ao templo/igreja. A filiação religiosa é expressiva entre as jovens populares (em contraste com os rapazes de mesma inserção social): a maioria se declara pentecostal (6); há também afro-brasileira (1), católica (1), e sem religião (2).

A formação escolar desempenha forte papel de diferenciação entre os segmentos sociais. Sete informantes são estudantes; três rapazes já concluíram os estudos. Todos os jovens de CM atingiram o nível superior de escolaridade - dois possuem pós-graduação. Encontramos maior diversidade em termos de escolaridade entre os jovens populares: a formação varia desde o nível fundamental incompleto (1) até o ingresso em cursos de nível superior, ainda que sem conclusão (3). Quanto à trajetória escolar das moças, todas as de CM atingiram o nível superior: três o completaram, uma estava cursando-o e outra havia interrompido na ocasião da gravidez (porque também trabal hava). Entre as jovens $(\mathrm{P}$, há duas com nível fundamental incompleto; duas com médio incompleto e três com médio completo; duas com superior incompleto euma com pós-graduação em curso.

A maioria dos rapazes desempenha alguma atividade profissional. As remunerações variam em torno de $R \$ 300,00$ a $R \$ 700,00$ entreos populares, e de $R \$ 700,00$ a $R \$ 2500,00$ entre os de segmento médio (em 2008, o valor do salário mínimo era de $R \$ 450,00)$. Das 15 jovens, apenas duas (CP) não estavam trabalhando no momento da entrevista, uma por estar desempregada e outra por estar trabalhando de forma esporádica, nos finais de semana, em barracas de festas de rua, vendendo alimentos. As remunerações giram em torno de $R \$ 200,00$ a $R \$ 800,00$ entre as populares, e de $R \$ 730,00$ a $R \$ 3600,00$ entre as de segmento médio.

Estratégias e itinerários de aborto na juventude

$\mathrm{Na}$ juventude, a ocorrência do aborto está diretamente vinculada ao aprendizado gradual das regras queorganizam o relacionamento amoroso e sexual entre díades heterossexuais. Em particular, está em jogo a socialização dos meandros de negociação entre parceiros e regras de gênero sobre provimento do método, cuidado e 
responsabilidade contraceptivos. N esse cenário, entremeiam-se perspectivas de gênero contrastantes, posições diferenciadas no controle da fecundidade, na divisão do trabalho reprodutivo e no desfecho de uma gravidez imprevista. A elucidação dessas múltiplas dimensões permite uma sociologia do aborto nessa fase da vida.

Neste artigo utilizamos duas categorias para identificar as circunstâncias em torno de uma interrupção da gravidez: estratégias e itinerários. Por estratégias concebemos o conjunto de ações que a gestante aciona para decidir e realizar 0 aborto: a rede de interlocutores, de apoios materiais e de informações indispensáveis para obter um procedimento clandestino. Por itinerário entendemos o elenco de métodos utilizados, a sequência temporal para obtenção do resultado esperado e eventuais sequelas do(s) procedimento(s). Paranós, o itinerário éo resultado concreto das estratégias acionadas, podendo incluir as dificuldades para conseguir os meios materiais para realizar aborto.

Os estudos sobre a magnitude do aborto no país mostram que a entrada do M isoprostol na década de 1990 - vendido em farmácias e, poste riormente, proibido, mas comercializado ilegalmente - passou a ser um importante método utilizado pela população feminina para induzir aborto ${ }^{17}$. Tais investigações apontam as complicações decorrentes deste procedimento. Este trabalho mostra os diferentes recursos acionados, em que o M isoprostol é apenas um dos diversos métodos utilizados para interromper a gravidez. É flagrante a heterogeneidade de situações encontradas entre as moças pertencentes aos segmentos populares. Estratégias variadas culminam no tipo de método utilizado e espel ham o grau devulne rabilidade e/ou autonomia das envolvidas. Assim, dentre os 16 casos de interrupção da gestação (10 informantes), o recurso mais utilizado foi: "curiosas", em 7 casos, seguido de clínicas médicas privadas (6), uso do Misoprostol (2), e chás e infusões (1). Em três episódios ocorre a combinação de métodos abortivos: uso de M isoprostol e posterior recurso à clínica; ingestão de chás, seguido de M isoprostol e ida a uma "curiosa"; ingestão de chás e recurso à "curiosa".

Sobressai nesse quadro o baixo uso do M isoprostol. Tal resultado contrariou a expectativa de um maior número de narrativas envolvendo 0 medicamento, em razão deseu menor custo ecrescente popularização, se comparado às clínicas.

É necessário qualificar o tipo de clínica médica à qual mulheres, com menor poder aquisitivo, recorrem. As narrativas de duas moças de $\mathrm{CP}$, que realizaram seus abortos (com 1 ou 2 meses de gestação) em clínicas situadas em área nobre da cidade, se aproximam daqueles proferidas por jovens deCM $\mathrm{O}$ pertencimento às classes populares dessas duas deveu-se à origem social da família, local de moradia e renda. Contudo, ambas apresentam uma trajetória escolar ascendente: a primeira concluía a graduação e a segunda possuía o segundo grau etrabal hava à época do evento. Os abortos realizados são mais caros, variando de $R \$ 500,00$ a $R \$ 1200,00$. As duas entrevistadas saíram dos respectivos locais em que fizeram a interven ção com tel efones de contato para o caso de complicação; fato não ocorrido. Ambas as histórias trazem a narrativa deaflição diante do possível conhecimento da gestação por parte dos pais. Elas obtêm ajuda, em um caso, do noivo e da cunhada e, em outro, de um grande amigo. Salientam-se assim as estratégias de busca de apoio para o aborto e de ocultamento da gravidez.

Os outros quatro eventos concernentes à interrupção da gravidez em clínicas clandestinas ocorreram em áreas menos privilegiadas da cidade. Nestes eventos, 0 itinerário até a interrupção da gravidez é direto, do ponto de vista do método escolhido, não havendo uso de chás ou outros procedimentos; e há intenso envolvimento eparticipação das famílias de origem, da moça e/ou do parceiro, no processo decisório.

Podemos ilustrar tal perfil a partir do caso da jovem Ticiane ( 25 anos), cuja primeira gravidez/ aborto ocorreu aos 14 anos de idade. Ela não tem o apoio do parceiro para seguir com a gestação. Com pouca idade, para a decisão concorrem sua mãe, a mãe e o irmão do parceiro como atores essenciais no processo que leva à interrupção da gravidez, obtida pela ingestão de chás, uso de M isoprostol e duas idas a uma mesma clínica clandestina. M ãe e'sogra' se opõem em relação ao desfecho da gestação; 0 aborto é realizado a despeito da opinião contrária da mãe da moça.

O M isoprostol é identificado como o agente efetivo e único de interrupção da gestação em apenas dois casos. Há menos atores envolvidos na negociação e é menor o tempo de gestação (2 e 3 meses). Em um dos eventos, a moça leva dois meses para contar ao parceiro que estava grávida por saber que ele não queria ter (mais) filhos. Ela atribui a decisão pelo aborto ao parceiro, pois por si manteria a gestação; ele providenciou a compra do medicamento. Não há relato de complicações neste episódio, o que difere muito dos outros dois abortos de sua trajetória.

A outra interrupção com o medicamento é de Natasha ( 26 anos, CP, 1 aborto, 3 filhos). Esta 
informante precisou ser conduzida ao hospital por complicações pós-aborto. Ela aciona uma amiga na impossibilidade de recorrer à família, pois a gravidez fora mantida em segredo. Entretanto, todos ficaram sabendo do aborto porque ela passa mal.

Itinerários bastante sinuosos para conseguir a interrupção da gravidez e com diversas consequências decorrentes estão presentes nos relatos de moças populares que se situam em posições demaior vulnerabilidadesocial. Verdadeiros dramas sociais marcam as biografias dessas mulheres. As desvantagens econômicas e sociais as impelem a recorrer a "curiosas" - mulheres que moram em locais periféricos da cidade ou em comunidades faveladas e que usam "um líquido", "botam uma sonda" e depois o "neném sai". Estes abortos, em geral, são feitos de forma escondida de familiares e/ ou parceiros, mas com 0 auxílio de amigas.

Dayane ( 23 anos, CP, 2 filhos) fez quatro abortos com uma "curiosa". A primeira interrupção aos 20 anos, quando tinha uma filha pequena. Afirma que não tinha apoio para interromper a gravidez; já não morava mais com seus familiares e o parceiro era contra o aborto. No quarto mês de gravidez, ela conseguiu obter dele o dinheiro para interromper a gestação. Esta foi a primeira dentre as quatro vezes que recorreu à mesma "curiosa":

Ela bota um líquido na seringa ejoga lá dentro. [...] Vai sangrando, você começa a sentir dor e é como se fosse um parto. É horrível a sensação. [...] Demorou umas dez horas. Eu cheguei lá era uma hora da tardeeno dia seguinte, quando foi noveda manhã eu já tinha expelido a criança. [...] Depois de vinte e quatro horas que eu fui para o hospital fazer a curetagem, porque ficam restos dentro e tem que limpar.

Dayane usou diversas vezes a pílula do dia seguinte, até quando profissionais do posto de saúde que frequentava recusaram-se a entregar o medicamento. Em todas asinterrupções de gestação, ela precisou ser levada para o hospital por complicações pós-aborto. Na última vez, "quase morreu". A pesar das advertências da "curiosa", o procedimento foi realizado em estágio avançado de gestação, pois "estava desesperada".

Bruna (22 anos, CP, 3 abortos, 2 filhos) fez dois abortos com "curiosas" e em ambas as situações houve complicações. Aos 20 anos, com uma filha pequena e face a uma gestação resultante de um parceiro eventual, ela não hesita em interrompê-la. Primeiramente, tenta o chá de"buchinha do norte", indicado por uma amiga. Como não surtiu efeito, informa à mãe estar grávida, a qual providencia o dinheiro $(R \$ 70,00)$ para 0 aborto. A entrevistada retorna à casa da "curiosa" para aplicar o "remédio novamente":

Aí, eu consegui, caiu o nenêem casa, fui para o hospital, porque estava sentindo muita dor, estava perdendo muito sangue. Ele caiu dentro do vaso [...] Era uma bolinha desanguepequenininha, não deu nem para ver, só sabia por que tinha sangue saindo. [...] Fiquei internada uma semana, não falei que tinha feito aborto. Falei que eu tinha caído (... ) fiquei no soro, depois fiz a curetagem. Três dias com hemorragia, fiz outra curetagem, depois me deram alta.

Situação dramática é vivida por Thainá ( 24 anos, CP, 2 filhos - uma tentativa de aborto e 1 aborto). Ela tem apenas o fundamental incompleto; trabalha em barracas de festas de rua preparando alimentos e em "biscates quando aparece". Diz que ela e seu parceiro não queriam a segunda gestação, pois o primeiro filho era recente. $\mathrm{Na}$ tentativa de aborto, primeiramente ela toma o M isoprostol; sem sucesso, procurou uma "curiosa". A sonda utilizada perfurou os rins e 0 intestino. 0 feto sobreviveu sem sequelas. Thainá ficou em coma por três dias eafirma que"quase morreu". Vivendo em um relacionamento violento, ela se separa do parceiro. Aos 21 anos, engravida de novo, em uma relação sexual ocasional. M ais uma vez, faz uso de diversos procedimentos para interromper a gestação: chás de "buchinha do norte", de maconha, de cachaça com arruda, de cogumelo fervido com vinho, de folha de café; M isoprostol, mas nada funcionou. Foi então que recorreu a outra "curiosa", que utilizou um líquido etalo de mamona. Vintee quatro horas depois de ter feito o procedimento, passando muito mal, com cólica e febre, resolveu ir para o hospital:

umas duas a três horas do negócio já em mim, eu já comecei a sentir cólica... sangrando, aí começou a me dar febre. Fui parar no hospital [...] Me deu a convulsão, até então eu tava naquela que 0 feto ia descer... E o feto já estava morto dentro de mim e eu não sabia. Devido a ele já estava morto, a dor veio, mas eu num..., ele tava agarrado na placenta.

O caso ilustra como a relação das mulheres com os serviços de saúde, em situações de aborto, pode ser complicada. Levada para o hospital público, que se recusa a recebê-la, seu pai aciona a polícia para a filha ser atendida.

Em absoluto contraste com os casos de aborto descritos estão os realizados por moças de camadas médias. Os percursos são mais lineares: 
passa-se rápido da descoberta da gravidez à certeza da interrupção, não havendo em suas trajetórias espaço para hesitação ${ }^{18}$. Não há ingestão de chás ou M isoprostol; as clínicas médicas privadas são as eleitas. Não há qualquer relato de complicação pós-aborto, o que faz supor que sejam clínicas de 'bom padrão', com procedimentos mais seguros eassépticos, ainda que clandestinas. $O$ depoimento de Regiane ( 24 anos, CM , um aborto aos 19) ilustra tal distinção:

Elesfizeram uma coisa muito bem feita. Eu contei para o meu ginecologista, eu fiz vários examese não tiveproblema algum. Vocêfica limpinha. Quando eu cheguei lá eles me trataram bem, eu chorava muito, falavam que seu eu não quisesse fazer, que elesnão fariam. Eles medeixaram muito à vontade. Eu falei que queria fazer. M esmo sofrendo e chorando, a minha barriga estava crescendo já.

Outro elemento comum às narrativas de CM é o apoio dos pais. Quase sempre eles são os primeiros a saberem da gravidez da filha, sobretudo a mãe, e em geral pagam pelo procedimento. Apesar da decepção ou 'chateação', os pais se mostram favoráveis à decisão da filha. Em somente um caso, a família da moça não esteve a par da gestação. 0 aborto é realizado com apoio do parceiro e dos pais dele.

Em resumo, os casos de aborto descritos pelas jovens de CP remetem para a escassez dos recursos materiais e logísticos para abortar, recorrendo-se a métodos inseguros. As narrativas das jovens de CM ensejam abortos realizados em clínicas, com métodos mais seguros e menos invasivos. A diferença declassetambém reverbera no tempo gestacional em queo aborto érealizado. Jovens CP mencionaram ter feito 0 aborto no segundo trimestre da gestação, seja por dificuldades de obter os recursos financei ros para 0 procedimento, por indecisão e/ou obstáculos no processo de negociação com o parceiro e com as famílias. A ilegalidade da prática do aborto no Brasil torna esses casos de situação limite ainda mais dramáticos.

\section{A perspectiva masculina}

Há uma regularidade no que diz respeito à relação entre classe social e os itinerários abortivos. Não se encontra entre as CM qualquer mé todo de interrupção alternativo a clínicas particulares que ofereçam relativa segurança. São cinco abortos relatados pelos cinco rapazes de CM, todos realizados em clínicas; não há relato de sequelas ou uso subsequente de serviços públicos. 0 único aspecto variante entre os jovens en- trevistados (CM ) é a presença ou não deles durante o procedimento; com uma exceção, todos debateram 0 assunto com suas parceiras, participando, em certa medida, da decisão. A presença da família nos relatos, mães etias, em especial, sinaliza sua importância como suporte, viabilizando recursos para o procedimento e mesmo acompanhando à clínica. Assim, o respeito à decisão, o apoio material e a presença física são uma regularidade no universo de camadas médias pesquisado.

Entre os informantes de camadas populares, o itinerário abortivo apresenta outros destinos, escalas e dificuldades, muito além da segurança das clínicas da zona sul do Rio de Janeiro. 0 recurso ao M isoprostol é significativo: o medicamento é referido em seis das oito entrevistas. M enciona-se o recurso a chás abortivos em três entrevistas. Em síntese, é um itinerário mais arriscado e multifacetado do que aquele encontrado entre os sujeitos de CM. Na comparação entre os depoimentos masculinos e femininos, é mais frequente o recurso ao Misoprostol nos primeiros. Aventamos duas hipóteses, que demandam estudos futuros. A narrativa masculina sobre o aborto por meio do M isoprostol assinalaria maior envolvimento do parceiro no processo decisório; suas parceiras estariam mais amparadas, pois uma faceta relevante dos relatos masculinos é apontar o papel de provedor dos recursos para a interrupção da gravidez. 0 segundo argumento, complementar ao primeiro, supõe, a partir de indícios etnográficos, de que a escolha por "curiosas" indicaria um anseio da presença de um outro na cena do abortamento: a "curiosa" não só funciona como a "especialista" que conduz a ação, como representa um amparo em uma situação de solidão - em todos os relatos de "ida à curiosa" os parceiros estão ausentes. Por fim, a compra do medicamento é mais onerosa do que os preços praticados por "curiosas" em meios populares.

0 relato de Helder ( 25 anos, CP, 1 aborto) ilustra tais características: vários métodos utilizados na tentativa de interromper uma suspeita de gestação e logo depois uma gravidez efetiva. M orador de uma comunidade favelada, negro, estudante de universidade pública, Helder, aos 17 anos, estava em um namoro de sete meses com parceira um ano mais nova (imigrantenordestina, parda e com fundamental incompleto), quetrabal hava como babá em casa vizinhaà dele, com quem tem a sua iniciação sexual. Logo na primeira relação sexual, usam e abandonam o preservativo masculino porque, segundo ele, atra- 
palhava a sensibilidade. Passam a fazer coito interrompido ("nem sempre", segundo ele) e uma tabela queele define como "informal", o que configura uma prática contraceptiva de baixa eficácia. Com 4 meses de namoro, o par enfrenta a primeira suspeita de gravidez; a parceira tinha um ciclo bastante regular, a menstruação atrasa poucos dias eisto gera providências: elepede ajuda à mãe, queindica um chá de canela, não como abortivo, mas para fazer a "menstruação descer". De fato, ela menstrua, mas o susto, afirma Helder, faz com que voltem a usar preservativo. Uma nova suspeita de gravidez surge aos seis meses de namoro. Desta vez, o chá de canela não surte efeito; a gravidez é confirmada por exame de sangue. Os dois são contrários ao aborto, mas decidem interromper a gestação sob o argumento da juventude deambos, edeque uma gravidez atrapal haria os projetos - em especial o de $\mathrm{Hel}$ der, que pretendia entrar para a aeronáutica. A mãe dele empresta $R \$ 100,00$ para a compra do $M$ isoprostol, indicado por uma enfermeira amiga do informante. A parceira faz uma "lavagem" depois do suposto aborto, mas novos enjôos e uma ultra-sonografia confirmam que a gestação continuava. Agora sem o consentimento de $\mathrm{H} \mathrm{el}$ der, que havia decidido manter a gestação em conjunto com a parceira - eleinterpreta o aborto mal-sucedido como um sinal "metafísico" -, ela tenta mais uma vez interromper a gravidez, aos quatro meses de gestação, com Misoprostol e chá de maconha. Helder fica sabendo da nova tentativa através de uma parenta da parceira e a procura para tomar satisfação. Entre os relatos masculinos colhidos na pesquisa, talvez seja este o que melhor detalha a trágica cena do aborto feito em contexto inseguro:

Ela tinha feito 0 aborto, e eu vi a cena: ela estava lá, seminua, ensanguentada, de pé e chorando muito, e o feto ao lado, devia ter o que? Uns $10 \mathrm{~cm}$, por aí; e dava pra ver que era um menino... aí ela chorava... sabe, eu nunca vi em toda a minha vida alguém tão arrependido quanto ela, o desespero dela. [...] Disseram que 0 aborto dela foi um procedimento, como eu vou dizer, muito mal feito, muito feio, então que poderia ter consequências.

M isoprostol, ervas caseiras, maus tratos no sistema público de saúde e possível esterilidade compõem um itinerário particularmente doloroso, mas não de exceção, entre as camadas populares. Os relatos deixam poucas dúvidas sobre as dificuldades e a violência às quais são expostas as jovens pobres. A ilegalidade do aborto enseja dois contextos bastante distintos: aqueles que possuem redes mais articuladas e melhores pos- ses financeiras optam pelo procedimento feito em contexto de relativa segurança e cuidado; em outro registro, entre as pessoas com parcos recursos financeiros, encontramos relatos de uma multiplicidade de métodos, que inclui são só o recurso a clínicas clandestinas, mas também medicamentos, objetos ebeberagens. Fica evidentequeositinerários eos recursos utilizados estão em relação direta a diferenciais de classe social.

Sexualidade

e aprendizado do manejo contraceptivo

Diversas mudanças sociais e culturais ocorreram nas últimas décadas na esfera da sexualidadee das relações de gênero. 0 exercício sexual na adolescência ainda tem sido tratado sob a ótica do risco, mas ganhou maior legitimidade social. Há um universo novo e complexo de relações no âmbito dos casais jovens que merece ser aprofundado sob o ângulo da experimentação sexual na juventude. Partimos da premissa de que adolescentes e jovens aprendem as regras sociais que estruturam as relações entre os gêneros, num processo contínuo de apropriação dos códigos que regulam a interação sexual do $\operatorname{par}^{19}$.

Na mesma esteira, propomos haver forte vínculo entre os temas da contracepção e da sexualidade, supondo a existência de um aprendizado relacional e gradual dos códigos, nos quais a lógica de gênero tem papel decisivo. 0 manejo da contracepção inscreve-se em um processo de aprendizado e de tomada de decisões no qual o conhecimento dosmétodosnão éúnico el emento decisivo ${ }^{20}$. A inexistência de discussões públicas sobre sexual idadenessa etapa da vida produz uma expectativa irreal de incorporação automática da postura contraceptiva ${ }^{6}$, sobretudo entre jovens escolarizados. Pressupõe-se que acesso à informação transforme de imediato as práticas sexuais juvenis, instaurando uma conduta de autoproteção que eliminaria possíveis riscos. Entretanto, a introdução e o manejo dos métodos são lentos, demandam discussão entre parceiros, autoconfiança e apoio social ${ }^{21}$. Tais determinação e disciplina dificilmente são compatíveis com o domínio dos "primeiros passos" sexuais. Assim, a ocorrência de uma gravidez pode integrar esse percurso, tendo em vista que a interiorização das lógicas de contracepção e seu subsequente controle estão em processo de assimilação.

A forma espontânea e pouco reflexiva do exercício da sexualidade, característica difundida na sociedade brasileira, corporifica-se na forma como os jovens lidam com a contracepção. Dis- 
tanciamo-nos da interpretação calcada no argumento da irresponsabilidade juvenil, e enfatizamos as diretivas culturais que modelam uma conduta de fraca reflexibilidade no que concerne às questões sexuais. N este panorama, os estereótipos de gênero são poderosos, a contracepção é tida como assunto da alçada feminina, e a opinião das mulheres acerca da decisão do aborto deve ser respeitada, a despeito da frequente discordância dos parceiros quanto ao desfecho das gestações imprevistas. Um elemento suplementar para a sociologia do aborto nesta fase da vida é o papel preponderante do apoio financeiro de parentes para sua consecução, salvo em alguns poucos casos de moças de camadas populares.

Ainda que se conviva no Brasil com a ilegalidade do aborto enquanto aspecto jurídico formal, esta prática é cercada por um contexto moral que dilui a ilegalidade social. $N$ as classes médias, onde se encontra, via de regra, uma posição a favor da legalização do aborto - vige um ethos de não ocultamento da gravidez ede possibilidade decompartilhamento da experiência do aborto. Em termos práticos, o aborto é realizado de forma mais segura e veloz. Percebe-se uma mudança na percepção do aborto, que se desloca da esfera do segredo, atenuando-se seu caráter de tabu e sendo objeto de discussões intra einterfamiliares. 0 contexto financeiro mais confortável é um dado crucial para definir um aborto mais seguro e um itinerário curto que leva às clínicas, embora o contexto moral de apoio à possível interrupção não possa ser desprezado como aspecto que contribui para uma relativa segurança física e conforto psicológico gerado pela rede de apoio. Nas classes populares, a narrativa dos casos salienta a rejeição do aborto como princípio, enfatizando-se, contudo a impossibilidade de se ter mais um filho. Os relatos trazem maior dramaticidadena descrição dos itinerários eatestam uma vez mais a imensa iniquidade social presente no país.

\section{Colaboradores}

M L H eil lborn éresponsável pela concepção e coordenação da pesquisa, e pela redação do texto; CS Cabral fez a análise das biografias femininas e a elaboração do artigo; ER Brandão contribuiu para metodologia e revisão do texto; L Faro e F Cordeiro colaboraram na produção do panorama inicial; R Azizeéresponsável pela análise dos relatos masculinos. 


\section{Referências}

1. Tabet P. Fertilité naturelle et reproduction forcée. La Construction sociale de l'inégalité des sexes. Des outils et des corps. Paris, M ontréal: L'H armattan; 1998.

2. Ramirez-Galvez MC. Os impasses do corpo: ausências e preeminências de homens e mulheres no caso do aborto voluntário [dissertação]. Campinas (SP): Unicamp; 1999.

3. M enezes GMS, Aquino EM L. Pesquisa sobre o aborto no Brasil: avanços e desafios para o campo da saúde coletiva. Cad Saude Publica 2009; 25(Supl. 2): S193-S204.

4. Martine G. Brazil's Fertility Decline, 1965-95: A Fresh Look at Key Factors. Population and Development Review 1996; 22(1):47-75.

5. Brasil. M inistério da Saúde (MS). Secretaria de Políticas de Saúde. Área Técnica de Saúde da MuIher. M anual dos comitês de mortalidade materna. $2^{\underline{a}}$ ed. Brasília: M S; 2002.

6. Bajos N, Ferrand M. De la contraception à l'avortement. Sociologie des grossesses non prévues. Paris: Inserm; 2002.

7. Diniz D, Corrêa M. Aborto e saúde pública:20 anos de pesquisas no Brasil. Brasília: MS; 2008.

8. Diniz D, Medeiros M. Aborto no Brasil: uma pesquisa domiciliar com técnica de urna. Ciênc. saúde coletiva 2010; 15(Supl. 1):959-966.

9. Olinto M TA, M oreira Filho DC. Estimativa de aborto induzido: comparação entre duas metodologias. Rev. Panam. Salud. Pública 2004; 15(5):331-336.

10. M onteiro M, Adesse L. M agnitude do aborto no Brasil: aspectos epidemiológicos e socioculturais. Rio de Janeiro: I M S/UERJ, IPAS/Brasil; 2007.

11. Osis MJ, Hardy EE, Faúndes A, Rodrigues T. Dificuldades para obter informações da população de mulheres sobre aborto ilegal. Rev Saude Publica 1996; 30(5):444-451.

12. Nations M K, M isago C, Fonseca W, Correia LL, Campbell OM. Women's hidden transcripts about abortion in Brazil. Social Science \& M edicine 1997; 44(12):1833-1845.
13. Leal OF, Lewgoy B. Aborto: uma contribuição antropológica à discussão. Revista de Filosofia Política 1998; 2:173-195.

14. Velho G. Antropologia e a problemática da classe social. Interseções 2009; 11(2):297-305.

15. Arilha M. Homens: entre a "zoeira" e a "responsabilidade". In: Arilha M, Ridenti S, Medrado B, organizadores. Homens e masculinidades. São Paulo: ECOS; 1998. p. 51-77.

16. Heilborn ML, Cabral CS. Parentalidade juvenil: transição condensada para a vida adulta. In: Camarano AA, organizador. Transição para a vida adulta ou vida adulta em transição? Rio de Janeiro: IPEA; 2006.

17. Barbosa RM, Arilha M. A experiência brasileira com o Cytotec. Rev. Estudos Feministas 1993; 1(2): 408-417.

18. Peres SO, Heilborn M L. Cogitação e prática do aborto entre jovens em contexto de interdição legal: 0 avesso da gravidez na adolescência. Cad Saude Publica 2006; 22(7):1411-1419.

19. Heilborn $M L$, Aquino EML, Bozon M, Knauth $D$, organizadores. 0 Aprendizado da sexualidade: reprodução e trajetórias sociais de jovens brasileiros. Rio de Janeiro: Garamond; 2006.

20. Cabral CS. Contracepção e gravidez na adolescência na perspectiva de jovens pais de uma comunidade favelada do Rio de Janeiro. Cad Saude Publica 2003; 19(Supl. 2):283-392.

21. Brandão ER, Heilborn ML. Sexualidade e gravidez na adolescência entre jovens de camadas médias do Rio de Janeiro, Brasil. Cad Saude Publica 2006; 22(7):1421-1430.

Artigo apresentado em 20/12/2012

Aprovado em 05/02/2012

Versão final apresentada em 21/02/2012 